features were also collected in pSS patients (disease duration, disease activity measured by ESSDAI, glandular vs extraglandular involvement, serological features and treatments received)

Statistical analysis: To evaluate differences between patients and controls, T-test or Wilcoxon test with continuity correction, were used for quantitative features and Fisher test for categorical variables. In order to test the presence of pSS as an independent risk factor for subclinical atherosclerosis, from other features as classic CVRFs or analytical data, first we adjusted logistic binomial regression in a bivariate analysis, to select possible predictors to be included in a multivariate analysis. Statistical significance was $\mathrm{p}<0.05$, and $\mathrm{OR} \mathrm{Cl} 95 \%$ vas calculated. R-Statistics v- 3.6

Results: All of the 76 patients included were women, with a mean age of 53.7 \pm 11.7 years. For both groups, no differences between prevalence of classical CVRFs were found. Subclinical atherosclerosis presence was higher in patients with pSS than in controls [OR $=4.17,95 \% \mathrm{Cl}(1.27-16.54), \mathrm{p}<0.001]$, as well as CIMT values $(0.79 \pm 0.43 \mathrm{~mm}$ vs. $0.66 \pm 0.27 \mathrm{~mm} ; \mathrm{p}=0.02)$. An association of subclinical atherosclerosis with erythrocyte sedimentation rate $[\mathrm{OR}=1.18,95 \% \mathrm{Cl}$ $(1.05-1.37), p<0.05]$ and Rheumatoid Factor $[\mathrm{OR}=1.28,95 \% \mathrm{Cl}(1.63-2.26)$ $\mathrm{p}<0.05]$.

Conclusion: This cohort showed a greater prevalence of subclinical atherosclerosis in patients with pSS, indicating this disease as an independent risk factor for presence of early vascular damage.

References:

[1] Vitali C et al. Classification Criteria for Sjögren Syndrome: a revised version of the European criteria proposed by the American-European Consensous Group. Ann Rheum Dis. 2002; 61: 554-8

[2] Touboul PJ et al. Mannheim carotid intima-media thickness and plaque consensus (2004-2006-2011). An update on behalf of the advisory board of the 3rd, 4th and 5th watching the risk symposia, at the 13th, 15th and 20th European Stroke Conferences, Mannheim, Germany, 2004, Brussels, Belgium, 2006, and Hamburg, Germany, 2011. Cerebrovasc Dis. 2012; 34 : 290-6

Disclosure of Interests: Marta Novella-Navarro: None declared, José Luis Cabrera-Alarcón: None declared, José Luis Rosales Grant/research support from: I have received financial support from Novartis, UCB, Pfizer, Abvie to meeting and symposia, Jorge Juan González Martin Grant/research support from: I have received finacial grants from Novartis, Lilly, Pfizer, Abvie for meetings and symposia assistance, Paloma García de la Peña Grant/research support from: I have received finacial grants from Novartis, Lilly, Pfizer, Abvie for meetings and symposia assistance, Ofelia Carrion: None declared

DOI: 10.1136/annrheumdis-2020-eular.989

\section{AB0438 MALIGNANCIES IN PATIENTS WITH PRIMARY SJOGREN'S SYNDROME}

Ö. Özdemir Ișık ${ }^{1}$, A. Yazici ${ }^{1}$, A. Cefle ${ }^{1} .{ }^{1}$ Kocaeli University School of Medicine, Rheumatology, Kocaeli, Turkey

Background: Sjogren's syndrome (SS) is a chronic, systemic, autoimmune disease. The risk of developing lymphoproliferative malignancies is high in primary Sjogren's syndrome(pSS).

Objectives: In this study, we planned to present malignancy data in patients who were followed up in our outpatient clinic with a diagnosis of pSS.

Methods: Data of 151 patients diagnosed with pSS between 2004-2019 were retrospectively reviewed and clinical, demographic characteristics of 15 patients diagnosed with malignancy were examined.

Results: All 15 patients with malignancy were female, their mean age was $59 \pm$ 13 years, and the disease duration was $9 \pm 1$ years.

In this group, $7 \%$ of the patients had fever, $13 \%$ had weight loss and $7 \%$ had night sweats. Dry eye was present in $87 \%$, dry mouth in $93 \%$, LAP in $53 \%$ (Table 1). None of the patients had myositis, neuropathy and vasculitis. In $87 \%$ of the patients, schirmer was below $5 \mathrm{~mm}$ and in $67 \%$ of the salivary gland scintigraphy, decreased involvement in the parotid and submandibular gland was detected. Salivary gland biopsy was compatible with pSS diagnosis in $53 \%$ of patients. Rheumatoid factor, ANA, SS-A and SS-B were positive in $\% 60, \% 93$, $\% 67$ and $\% 53$ of patients, respectively.

Table 1. The data of pSS patients with malignancy

$\begin{array}{lr}\text { Gender (Female) } & \mathrm{N}(\%) \\ \text { Dry mouth } & 15(100) \\ \text { Dry Eye } & 14(93) \\ \text { Arthritis } & 13(87) \\ \text { Parotitits } & 3(20) \\ \text { Raynaud Phenomenon } & 4(27) \\ \text { Lymphadenopathy } & 2(13) \\ \text { Interstitial Lung Disease } & 8(53) \\ \text { Smoking } & 4(27) \\ \end{array}$

Table 1. The data of pSS patients with malignancy

\begin{tabular}{lc}
\hline Hypocomplementemia & $4(27)$ \\
Malignancy & $2(13)$ \\
Lung Cancer & $4(27)$ \\
Breast Cancer & $3(20)$ \\
Thyroid Papillary Cancer & $2(13)$ \\
Cervical Cancer & $1(7)$ \\
Vulva Cancer & $1(7)$ \\
Mycosis Fungoides & $1(7)$ \\
MALT lymphoma & $1(7)$ \\
Diffuse Large B Cell Lymphoma &
\end{tabular}

Low C3 level was detected in $27 \%$ of patients and C4 level was normal in all patients. Hypergammaglobulinemia was detected in $\% 27$ patents but data of five patients could not be reached. Malignancy was detected in $10 \%$ of the patients who were followed up with the diagnosis of PSS. Two patients had cervical cancer (CA), four had breast $C A$, three had thyroid papillary $C A$, one had diffuse large b cell lymphoma, one had MALT (mucous-associated lymphoid tissue) lymphoma, one had mycosis fungoides, one had vulva epithelial carcinoma and two had lung CA. Patients with malignancy and those without were compared in terms of clinical and laboratory findings. There was a significant relationship between presence LAP and smoking with development of malignancy. Subgroup analysis was performed according to titers of C-Reactive protein (CRP) and erythrocyte sedimentation rates (ESH), but there was no significant relationship between laboratory findings and the development of malignancy. (Table 2)

Conclusion: According to 2015 data of Turkey unified database for all age groups, the rate of cancer in woman is $25 \%$ for breast cancer, $12 \%$ for thyroid CA, $5.1 \%$ for lung CA, 2.5\% for cervical CA, 2.8\% for non-hodgkin lymphoma. Patients with pSS have a 6 to 19-fold increased risk for the development of non-Hodgkin B-cell lymphoma. For these reasons, detailed questioning and physical examination gain importance in the follow-up of patients

References:

[1] E Theander, G Henriksson, O Ljungberg.Lymphoma and other malignancies in primary Sjögren's syndrome: a cohort study on cancer incidence and lymphoma predictors. Ann Rheum Dis. 65 (6):796-803 2006

Table-2. Relationship between presence of malignancy and clinical and laboratory findings

\begin{tabular}{lccccc}
\hline N(\%) & $\begin{array}{c}\text { Malignancy( } \\
\mathbf{1 5}\end{array}$ & $\begin{array}{c}\text { Malignancy(-) } \\
\mathbf{1 3 6}\end{array}$ & $P$ & OR & $\% 95 \mathrm{Cl}$ \\
& & & & & \\
\hline Hypocomplementemia & $4(27)$ & $11 / 96(12)$ & 0,119 & 2,81 & $0,76-10,3$ \\
Fever & $1(7)$ & $7(5)$ & 0,576 & 1,31 & $0,15-11,4$ \\
Night Sweats & $1(7)$ & 0 & $\star$ & $*$ & $*$ \\
Weight Loss & $2(13)$ & $10(7)$ & 0,339 & 1,93 & $0,38-9,81$ \\
Smoking & $7(47)$ & $24(20)$ & 0,043 & 3,6 & $1,19-10,9$ \\
LAP & $8(53)$ & $36(27)$ & 0,039 & 3,17 & $1,07-9,38$ \\
Hypergammaglobulinemia & $4 / 10(40)$ & $26 / 86(30)$ & $*$ & $*$ & $*$ \\
ESH>50mm/h & $2(13)$ & $8(6)$ & 0,260 & 2,46 & $0,47-12,8$ \\
CRP>3XNormal & $2(13)$ & $14(10)$ & 0,662 & 1,34 & $0,27-6,56$ \\
& & & & &
\end{tabular}

*No analysis was done because the data was not enough

Disclosure of Interests: None declared

DOI: 10.1136/annrheumdis-2020-eular.2617

\section{AB0439 LUNG FINDINGS IN PATIENTS WITH PRIMARY SJOGREN'S SYNDROME}

Ö. Özdemir Işık ${ }^{1}$, A. Yazici ${ }^{1}$, A. Cefle ${ }^{1} .{ }^{1}$ Kocaeli University School of Medicine, Internal Medicine, Division of Rheumatology, Kocaeli, Turkey

Background: Sjogren's syndrome (SS) is a systemic, autoimmune disease and can affect many organs and systems.

Objectives: In this study, we planned to present the lung findings of primary SS (pSS) patients who are being followed in our outpatient clinic.

Methods: Chest radiographs and thorax CTs of 151 patients who were admitted to the rheumatology outpatient clinic between 2004 and 2017 and diagnosed as pSS according to the classification criteria of the American-European consensus group Sjogren's syndrome were retrospectively scanned.

Results: In our study, $97 \%$ of pSS patients were female and $3 \%$ were male and the mean age was $56 \pm 12$ years, disease duration was $10.5 \pm 5$ years.

It was observed dry eye in $86 \%$ of patients, dry mouth in $88 \%$, parotitis in $17 \%$, arthritis in $29 \%$, vasculitis in $4 \%$, neuropathy in $6 \%$, myositis in $1 \%$, lymphadenopathy in $29 \%$ (LAP), and $20 \%$ of patients had Raynaud phenomenon. In $50 \%$ of the patients, chest radiography was normal, and there were no respiratory complaints. Thorax CT was requested due to suspicious appearance on $50 \%$ chest x-ray. 